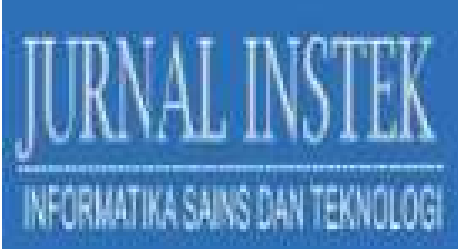

Volume 5 Nomor. 1, April 2020

P -ISSN : 2541-1179, E-ISSN : 2581-1711

Ojs :http://journal.uin-alauddin.ac.id/index.php/instek/index

Email : instek@uin-alauddin.ac.id

PEMANTAUAN HEMOGLOBIN DARAH DENGAN NON-INVASIVE MENGGUNAKAN SENSOR NEAR INFRARED LED IR 940NM

\author{
USMAN UMAR ${ }^{1)}$, RISNAWATY ALYAH ${ }^{2)}$ \\ ${ }^{1)}$ Prodi Teknologi Elektro-medis Politeknik Kesehatan Muhammadiyah, Makassar \\ Jln. Dr.Ratulangi No; 101 Makassar \\ ${ }^{2}$ Dosen Jurusan Teknik Elektro Universitas Sawerigading, Makassar \\ Jln . Kandea 1 No; 20 , Makassar \\ 1)Usmanmr4@gmail.com, ${ }^{2)}$ risna.alyah1202@gmail.com
}

\begin{abstract}
ABSTRAK
Kandungan hemoglobin umumnya digunakan dalam analisis klinis dalam mendiagnosis anemia, mengidentifikasi perdarahan, dan mengelola transfusi sel darah merah. Saat ini pengukuran hemoglobin darah pada umumnya dengan sistem invasif yang mengambil sampel darah dengan melukai dan dilakukan di klinik, pusat kesehatan, dan rumah sakit dengan biaya tinggi sehingga bagi masyarakat miskin bisa sulit untuk melakukan pemeriksaan rutin. Penelitian ini bertujuan untuk mengembangkan alat ukur hemoglobin darah sistem noninvasif. Sistem noninvasif ini menggunakan sensor Near Infrared (NIR) dengan LED dan Photodiodes dengan panjang gelombang $940 \mathrm{~nm}$. Metode pengembangan alat ini dengan tahapan, antara lain, persiapan pembuatan alat dengan melakukan studi literatur menghasilkan model dan pembuatan alat serta alat pengujian. dengan membandingkan teknik invasif dan non-invasif. Hasil penelitian ini menghasilkan alat ukur hemoglobin yang sederhana, mudah digunakan dan tanpa mengambil sampel darah untuk secara rutin mengukur hemoglobin dengan biaya rendah. Analisis hasil pegujian dengan menggunakan analysis varian dan uji-t yang menunjukkan bahwa alat yang didesain dapat digunakan untuk memantau hemoglobin darah..
\end{abstract}

Kata Kunci: Hemoglobin, Invasive .non-invasive, Sensor, ANOVA

\title{
I. Pendahuluan:
}

Darah dalam tubuh manusia terkandung berbagai unsur antara lain eritrosit yang merupakan sumber warna merah pada darah, warna merah darah dapat dipengaruhi oleh hemoglobin yang terdapat dalam eritrosit pada saat hemoglobing mengikat oksigen atau oksihemoglobin $(\mathrm{HbO} 2)$. . Hemoglobin merupakan salah satu analit paling penting dalam penelitian biokimia dan biomedis Metode standar yang terbaik untuk menentukan konsentrasi hemoglobin dalam darah dapat memberikan hasil yang tepat tetapi membutuhkan reagen dan lisis darah

Penelitian tentang teknik non-invasive dengan menggunakan sensor near infrared 


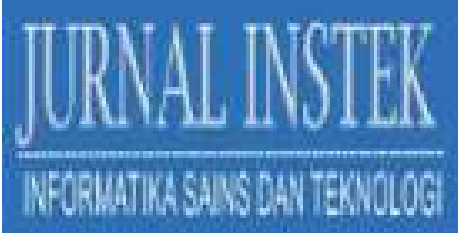

Volume 5 Nomor. 1, April 2020

P -ISSN : 2541-1179, E-ISSN : 2581-1711

Ojs :http://journal.uin-alauddin.ac.id/index.php/instek/index

Email : instek@uin-alauddin.ac.id

(NIR) untuk pengukuran komponen dalam darah antara lain glukosa darah, sensor NIR dengan Emmiter LED1550E, Photodioda FGA10 dengan panjang gelombang 800 1800nm., panjang gelombang $940 \mathrm{~nm}$ dengan radiasi NIR di $700-1100 \mathrm{~nm}$. Pengukuran kolesterol darah dengan sensor optik IR LED Photodiode panjang gelombang $800 \mathrm{~nm}-$ $1800 \mathrm{~nm}$.. Penelitian yang mengembangkan pengukuran $\mathrm{Hb}$ dengan teknik noninvasif yang tidak melukai untuk mengambil setetes sampel darah. Penegembangan cara noninvasive teresebut antara lain pengaukuran $\mathrm{Hb}$ dengan pemanfaatan cahaya untuk menentukan $\mathrm{Hb}$ dengan noninvasif. . Penggunaan multiwavelength dari sensor oximetry pulse yang merupakan salah satu metode pemantauan $\mathrm{Hb}$ noninvasif.. Pengukuran hemoglobin dan saturasi oksigen darah setara karena oksigen diikat oleh hemoglobin, sehingga hemoglobin adalah unsur yang bersama dengan oksigen yang diangkut sebagai muatan, semenatara dalam plasma darah terdapat glukosa, apabila meningkatnya kekentalan plasma darah menyebabkan kadar kadar glukosa tinggi, sehingga absorbsi cahaya pada sensor akan besar. Sehingga sensor oxymeter dapat digunakan untuk memantau hemoglobin, saturasi oksigen dan glukosa darah.[7. Salah satu cara mengukur saturasi oksigen dan kadar hemoglobin dalam darah dengan metode non-invasive adalah Pulse Oxymeter dengan menggunakan pancaran cahaya merah pada panjang gelombang $660 \mathrm{~nm}$ dan cahaya inframerah $940 \mathrm{~nm}$ sebagi emitter kemudian pantulan cahayan dideteksi oleh photodioda.. Alat ukur elektronik yang dapat mengukur dua parameter darah yaitu hemoglobin darah dan denyut jantung (elektro kardio graphi) secara bersamaan adalah alat ukur E-HEKG. Alat ini menggunakan beberapa komponen elektronika anatar lain photodioda, LDR, penguat tegangan, analog digital converter, dan mikrokontroler..

Panca indera manusia dapat melihat pada panjang gelombang 400-800 $\mathrm{nm}$ dengan energi sebesar 149-299 kJ/mol. Pada keadaan normal electron berada pada kulit atom yang memliki energi terendah (ground-state). Pada laruran cahaya dapat ditransmisikan tetapi sebagian cahaya yang dipancarkan diserap oleh larutan dan yang tidak terserap dipantulkan.

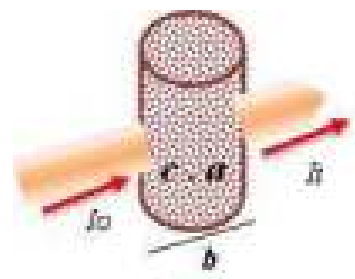

Gambar 1. Penyerapan cahaya pada larutan. 
Volume 5 Nomor. 1, April 2020

P -ISSN : 2541-1179, E-ISSN : 2581-1711

Ojs :http://journal.uin-alauddin.ac.id/index.php/instek/index

Email : instek@uin-alauddin.ac.id

\section{II.METODE PENELITIAN}

Pengukuran Hemoglobin ( $\mathrm{Hb})$ darah dengan teknik non invasive, dengan cara melakukan penyinaran darah pada jaringan tubuh seperti jari tangan dengan menggunakan pajang gelombang. Pengembangan sensor spektroskopi near infrared dengan menggunakan infrared LED dan Photodioda untuk menentukan komponen darah seperti SPO2, Glukosa, Hemoglobin dan Heartbeat. Penelitian sebelumnya menunjukan hasil yang baik. Penyerapan cahaya pada panjang gelombang yang dimanfaatkan dengan melakukan pengukuran transmisi atau reflektansi. Penggunaan Inframerah merupakan teknik Spekroskopi pada wilayah panjang gelombang inframerah dengan spectrum elektromagnetik.

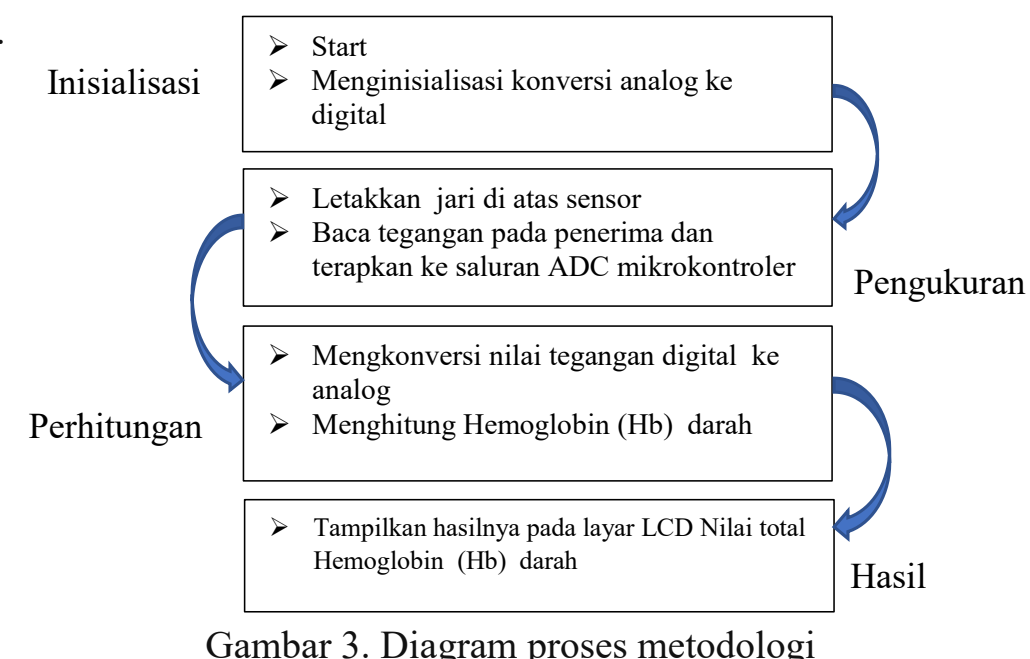

Diagram alur proses alat pemantau hemoglobin darah dengan melakukan pengolahan data yang dari sensor LED inframerah yang memancarkan cahaya ke jari, kemudian diserap oleh aliran darah, lalu dikonversi hasil serapan dan menghitung dengan perangkat lunak mikrokontroller dan hasilnya ditampilkan pada monitor LCD

Penelitian ini menggunakan sensor Near Infrared (NIR) dengan IR LED 333-A Everlight sebagai emitter dengan panjang gelombang $940 \mathrm{~nm}$, arus maju kontinu $100 \mathrm{~mA}$ dan arus maju puncak 1 A. Detektor yang digunakan adalah fotodioda PT 333-3C Everlight dengan rentang spektral bandwidth 400nm - 
Volume 5 Nomor. 1, April 2020

P -ISSN : 2541-1179, E-ISSN : 2581-1711

Ojs :http://journal.uin-alauddin.ac.id/index.php/instek/index

Email : instek@uin-alauddin.ac.id

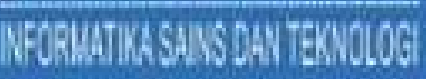

$1100 \mathrm{~nm}$, dan sensitivitas spektral pada panjang gelombang 940nm dan tegangan maksimum 5 volt. Fotodioda menyerap pantulan cahaya yang dipancarkan oleh emitter LED kemudian dikonversi menjadi tegangan output ke mikrokontroller. Alat pemantau kolesterol darah yang dirancang untuk mengkonversi tegangan output ke nilai hemoglobin darah dalam $\mathrm{mg} / \mathrm{dl}$

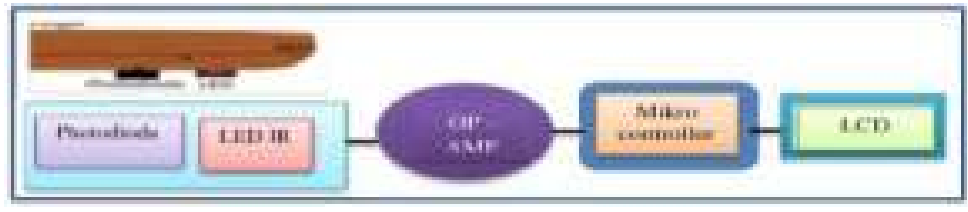

Gambar 4. Blok diagram monitor Hemoglobin darah $\backslash$

Rangkaian sensor yang terdiri dari LED IR $940 \mathrm{~nm}$ sebagai emitter yang memancarkan cahaya inframerah, Photodioda sebagai detektor yang menyerap atau menerima cahaya dan filter digunakan amplifier untuk mengurangi frekuensi suara dari sumber tegangan. Pada saat sensor dipasang pada jari tangan, cahaya dari LED akan diserap oleh jaringan pada jari tangan, dan yang tidak terserap terpantul dan diterima oleh detector photodioda. Cahaya yang diterima oleh photodioda menjadi nilai redaman cahaya dan diubah menjadi nilai arus listrik, kemudian menjadi tegangan dengan adanya resistor beban pada anoda. Tegangan di yang dikeluarkan oleh photodioda tergantung banyaknya pantulan sinar yang diterima, semakin banyak pantulan sinar yang diterima maka semakin tinggi tegangan dikeluarkan oleh photodiode yaitu antara $0 \mathrm{~V}$ sampai $5 \mathrm{~V}$. Nilai tegangan dari photodiode masih terlalu rendah sehingga variasi nilai tegangan kurang kelihatan perbedaannya, untuk mengatasi hal tersebut diperlukan penguatan tegangan dari sensor dengan menambahkan rangkaian penguat OP-AMP dengan LM358N yang dapat menguatkan sinyal dari sensor. Nilai tegangan dari photodioda dari rangkaian sensor dibaca oleh mikrokontroller ADC 10 bit dan nilai ADC ini dikonversi kembali menjadi nilai tegangan. kemudian nilai tegangan tersebut dimasukkan pada persamaan linear untuk mengubah menjadi nilai hemoglobin darah.

Pengujian alat dengan mengambil sampel sebanyak 20 orang dengan usia yang berbeda antara 20 - 50 tahun dengan partisipan laki laki dan perempuan Pengumpulan data total kolesterol darah menggunakan alat ukur invasif, dan 
beberapa menit kemudian dilanjutkan mengukur tegangan dengan sensor NIR yang dirancang. Pengumpulan data nilai keluaran tegangan sensor, setiap partisipan diukur lima kali. Metode pengumpulan data dengan mengukur tegangan keluaran sensor yaitu dua kali sebelum mengambil sampel darah untuk mengukur dengan teknik invasif kemudian tiga kali pengukuran sesudahnya. Stabilitas tegangan output sensor, selama sensor berada di jari selama sekitar 25 detik, maka data nilai tegangan sensor dirata-rata.

Analisa data dilakukan untuk menentukan nilai standar deviasi dan error setiap pengukuran dengan uji-t dan analisis varian (ANOVA). Setiap data diuji signifikansinya untuk menentukan diskriminasi dalam klasifikasi data. Nilai ratarata dan standar deviasi dihitung analisis statistik untuk mendapatkan p-value yang digunakan untuk pengukur akurasi parameter. Secara statistik bahwa data yang signifikan apabila nilai- $\mathrm{p}<0: 05$ dapat diterima, dan apabila nilai-p $>0$ :05 diabaikan atau tidak diterima

\section{HASIL DAN PEMBAHASAN}

Penelitian ini menghasilkan alat pemantau hemoglobin darah dengan teknik noninvasif menggunakan sensor IR led $940 \mathrm{~nm}$.

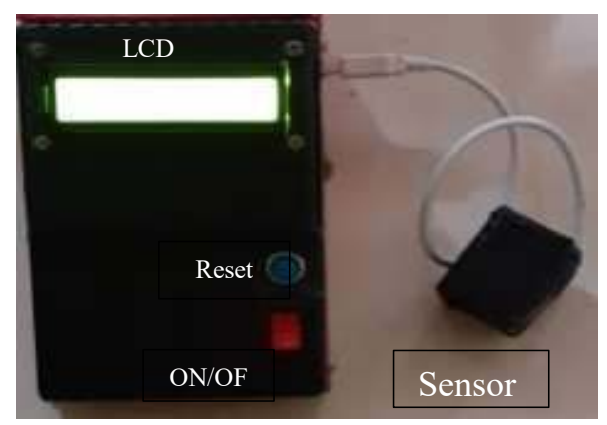

Gambar 5. Alat pemantau hemoglobin darah non invasive

Pengukuran hemoglobin yang dilakukan pada partisipan pria dan wanita dengan teknik pengukuran invasive dan dihubungkan dengan nilai tegangan output sensor memperlihatkan adanya hubungan linear. Perbedaan tegangan output sensor terlihat, disebabkan oleh penyerapan cahaya di jaringan tubuh dan refleksi cahaya yang berbeda. Hemoglobin darah setiap orang mempengaruhi perbedaan ini 
Volume 5 Nomor. 1, April 2020

P -ISSN : 2541-1179, E-ISSN : 2581-1711

Ojs :http://journal.uin-alauddin.ac.id/index.php/instek/index Email : instek@uin-alauddin.ac.id

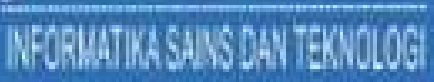

Tabel 1. Pengukuran Hemoglobin darah dan data output sensor

\begin{tabular}{|c|c|c|}
\hline \multirow{2}{*}{ SUBJECT } & $\begin{array}{c}\text { TEG. } \\
\text { SENSOR }\end{array}$ & HEMOGLOBIN \\
\cline { 2 - 3 } & $(\mathrm{V})$ & $(\mathrm{g} / \mathrm{dl})$ \\
\hline 1 & 1.98 & 8.1 \\
\hline 2 & 2.09 & 8.7 \\
\hline 3 & 2.16 & 9.8 \\
\hline 4 & 2.27 & 11.4 \\
\hline 5 & 2.34 & 13.5 \\
\hline 6 & 2.36 & 14.1 \\
\hline 7 & 2.44 & 15.1 \\
\hline 8 & 2.53 & 16.1 \\
\hline 9 & 2.65 & 17.3 \\
\hline 10 & 2.71 & 18.7 \\
\hline
\end{tabular}

Data pada tabel.1 di analisis dengan regresi linear untuk mendapatkan persamaan atau formulasi hubungan antara hemoglobin darah (y) dan tegangan output sensor (X). Hasil analisis regresi linear ditunjukkan pada gambar grafik berikut:

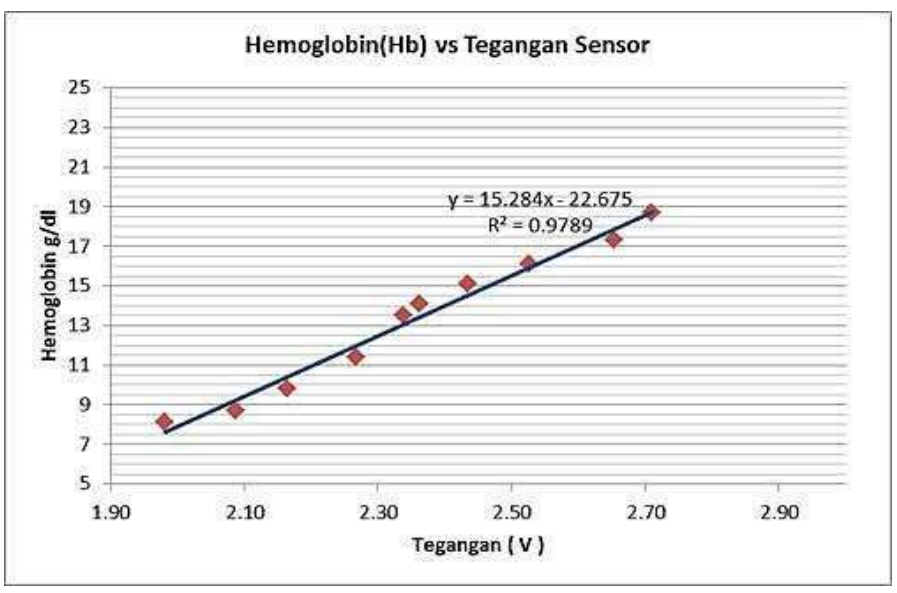

Gambar 6. Regresi linear hubungan antara hemoglobin darah dengan tegangan sensor

Hasil dari regresi linear dari hemoglobin dan tegangan output sensor diperoleh persmaan linear $\mathrm{Y}=15,284 . \mathrm{x}-22,675$, dengan koefisien korelasi regresi $\mathrm{R}^{2}=0.9789$, dengan nilai regresi square yang mendekati nilai 1 , menunjukkan bahwa tegangan output sensor NIR sudah linier dengan baik terhadap nilai hemoglobin darah yang diukur dengan teknik invasif. Persamaan linear ini 
digunakan dalam program mikrokontroller untuk mengkonversi nilai tegangan output sensor menjadi nilai hemoglobin darah $(\mathrm{Hb})$.

Pembaacaan sensor IR LED dan photodiode tersebut menunjukkan belum stabil, karena nilai regresi square $<1$. Factor-faktor yang mempengaruhi nilai rgresi square $<1$ antara lain pemasangan sensor tidak konsisten, kemungkinan cahaya lain yang diterima oleh fotodioda sehingga pantulan cahaya tidak murni dan Ketebalan kulit mempengaruhi penyerapan cahaya pada jaringan jari.

Pengujian alat pemantau yang telah didesai dilakukan validasi alat dengan membandingkan pengukuran hemoglobin invasif dengan alat pengukur non-invasif yang telah didesain. Data dari alat pengukur hemoglobin invasif sangat akurat karena menggunakan sampel darah, tetapi data dari alat pengukur kolesterol non-invasif tergantung pada deteksi sensor NIR. Beberapa sampel yang telah diambil untuk menguji konsep tersebut, untuk memvalidasi dengan metode, mengukur hemoglobin darah dua kali dengan teknik non-invasive sebelum mengambil sample darah untuk teknik invasive, dan diukur kembali dua kali dengan teknik non invasive

Tabel 2. Hasil pengukuran $\mathrm{Hb}$ invasive dan noninvasive

\begin{tabular}{|c|c|c|c|}
\hline SUBJECT & $\begin{array}{c}\text { INVASIVE } \\
(\mathrm{g} / \mathrm{dl})\end{array}$ & $\begin{array}{c}\text { NON } \\
\text { INVASIVE } \\
(\mathrm{g} / \mathrm{dl})\end{array}$ & $\begin{array}{c}\text { Error } \\
(\%)\end{array}$ \\
\hline $\mathrm{A}$ & 15.2 & 14.9 & $2 \%$ \\
\hline $\mathrm{B}$ & 16.3 & 16.0 & $2 \%$ \\
\hline $\mathrm{C}$ & 8.2 & 8.1 & $1 \%$ \\
\hline $\mathrm{D}$ & 11.2 & 11.6 & $4 \%$ \\
\hline $\mathrm{E}$ & 10.5 & 10.6 & $1 \%$ \\
\hline $\mathrm{F}$ & 7.8 & 7.6 & $2 \%$ \\
\hline $\mathrm{G}$ & 6.5 & 6.7 & $3 \%$ \\
\hline $\mathrm{H}$ & 8.7 & 9.2 & $6 \%$ \\
\hline $\mathrm{I}$ & 9.8 & 10.0 & $2 \%$ \\
\hline $\mathrm{J}$ & 11.4 & 11.6 & $2 \%$ \\
\hline
\end{tabular}

Dari Tabel 2, masih terlihat perbedaan data antara kedua perangkat tersebut dengan nilai error maximum 6\%. Dari data pengukuran $\mathrm{Hb}$ invasive dan non-invasif sesuai dengan metode pengambilan sampel, dari hasil data tersebut dilakukan regresi 
Volume 5 Nomor. 1, April 2020

P -ISSN : 2541-1179, E-ISSN : 2581-1711

Ojs :http://journal.uin-alauddin.ac.id/index.php/instek/index

Email : instek@uin-alauddin.ac.id

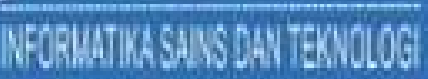

statistic dengan analisis varian (ANOVA) dengan single faktor untuk menentukan nilai regeresi square, standar error dan nilai $F$ table $(F$ Critical) $>$ F hitung.. Hasil analisi varian (ANOVA) seperti pada table berikut;

Tabel 4, Analisis ANOVA Single Factor

\begin{tabular}{|c|c|c|c|c|c|c|}
\hline Groups & Count & Sum & Average & Variance & & \\
\hline $\begin{array}{l}\text { INVASIVE }(\mathrm{mg} / \mathrm{dl}) \\
\text { NON INVASIVE } \\
(\mathrm{mg} / \mathrm{dl})\end{array}$ & 10 & 105.6 & 10.56 & 9.922667 & & \\
\hline \multicolumn{7}{|l|}{ ANOVA } \\
\hline Source of Variation & $S S$ & $d f$ & $M S$ & $F$ & P-value & F crit \\
\hline Between Groups & 0.02 & 1 & 0.025 & 0.0026 & 0.960 & 4.414 \\
\hline Within Groups & 171.73 & 18 & 9.540 & & & \\
\hline Total & 171.75 & 19 & & & & \\
\hline
\end{tabular}

Pada table ANOVA di atas menunjukkan bahwa nilai variance rata rata 9,1 sampai dengan 9,9 dan nilai P- value antara group 0,96 dan F hitung ; 0,026, analisis hipotesa bahwa nilai $\mathrm{F}<\mathrm{F}$ critical ( $\mathrm{F}$ table) dan nilai-P $>0.05$ (nilia signifikan), memperlihatkan hasil pengukuran yang berbeda antara teknik Invasif dan non-invasif. Sehingga hasil yang tunjukkan bahwa alat non invasive layak digunakan namun perlu perbaikan yang berkelanjutan

Uji - $t$ dengan menggunakan metode Two-Sample Assuming Equal Variances untuk membandingkan hasil uji- $\mathrm{t}$ dan data table, hasil uji $-\mathrm{t}$ terlihat pada table berikut:

Tabel 4, Analisa Ujik-t Two-Sample Assuming Equal Variances t-Test: Two-Sample Assuming Equal Variances

\begin{tabular}{lrr}
\hline & INVASIVE $(\mathrm{mg} / \mathrm{dl})$ & NON INVASIVE $(\mathrm{mg} / \mathrm{dl})$ \\
\hline Mean & 10.56 & 10.63 \\
Variance & 9.923 & 9.1579 \\
Observations & 10 & 10 \\
Pooled Variance & 9.5403 & \\
Hypothesized Mean Difference & 0 & \\
df & 18 & \\
$t$ Stat & -0.0507 & \\
$P(T<=t)$ one-tail & 0.4801 & \\
$t$ Critical one-tail & 1.7341 & \\
$P(T<=t)$ two-tail & 0.9601 & \\
$t$ Critical two-tail & 2.1009 & \\
\hline
\end{tabular}




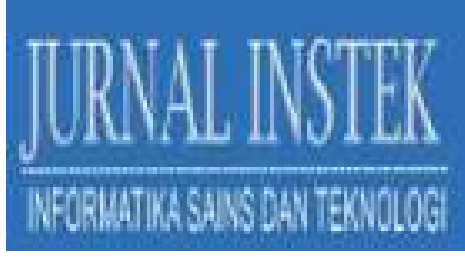

Volume 5 Nomor. 1, April 2020

P -ISSN : 2541-1179, E-ISSN : 2581-1711

Ojs :http://journal.uin-alauddin.ac.id/index.php/instek/index

Email : instek@uin-alauddin.ac.id

Analisa dengan Interpretasi hasil dalam table, hasil analisa varian single faktor ANOVA dengan menggunakan analisis statistik. Hasil olah data dengan ANOVA menunjukkan nilai-P $>$ F yang merupakan nilai-p untuk seluruh tes model, sebagai acuan untuk menentukan keputusan menerima atau menolak suatu hipotesa. Hipotesa diterima jika nilai-p lebih rendah dari nilai signifikan $(\alpha)$ direkomendasikan dan Hipotesa ditolak jika nilai-p lebih besar dari tingkat signifikan[14]. Hasil ANOVA menunjukkan nilai-p $>$ F nilai signifikan. berarti menunjukan hasil yang dapat diterima.

Uji-t menganalisis normalisasi data pengukuran menggunakan metode $t$-test dengan paired two sample for means . table 4 menunjukan uji-t dengan hasil t hitung ( $t$-stat) dihubungkan dengan nilai $t$ table (t-critical) diperoleh hasil t hitung lebih rendah dari t table $(-0,05<1,73)$ dan $\mathrm{P}(\mathrm{T}<=\mathrm{t}) 0,48>\alpha 0,05$, yang berarti bahwa terdapat selisih nilai antara teknik invasive dan non invasive, tetapi tidak berpengaruh signifikan, sehingga hasil dapat diterima dan terus dikembangkan untuk meningkatkan akurasi peralatan yang buat.

\section{IV.KESIMPULAN}

Data yang disajikan dalam penelitian ini hasil pengukuran hemoglobin menggunakan teknik noninvasif yang didesain dengan menggunakan sensor yang terdiri dari emitter IR LED dan Photodiode sebagai detektor. Hasil pengujian, validasi dan analisis pengukuran merupakan perbandingan antara prosedur teknik invasive dan prosedur teknik non-invasive. Pengembangan alat ini merupakan inovasi alternatif yang dapat digunakan untuk mengukur haemoglobin darah yang mudah digunakan dan tidak menyakitkan serta biaya rendah karena tidak menggunakan strip $\mathrm{Hb}$. Keakuratan instrumen berkembang cukup baik dan dapat diandalkan dari hasil persamaan linear yang menghasilkan nilai error dari 1\%sampai $6 \%$, dan analisis anova dan uji-t menunjukan bahwa hasil pengukuran dapat diterima.

\section{DAFTAR PUSTAKA}

A. Zainuri, "Pemanfaatan Sensor Cahaya Sebagai Alat Untuk Mengukur Kadar Hemoglobin Dalam Darah," no. May, 2016.

E. Kusumawati, N. Lusiana, I. Mustika, S. Hidayati, dan E. N. Andyarini, "The Differences in the Result of Examination of Adolescent Hemoglobin Levels Using Sahli And Digital Methods (Easy Touch GCHb)," J. Heal. Sci. Prev., vol. 2, no. 2, hal. 95-99, 2018. 
Volume 5 Nomor. 1, April 2020

P -ISSN : 2541-1179, E-ISSN : 2581-1711

Ojs :http://journal.uin-alauddin.ac.id/index.php/instek/index

Email : instek@uin-alauddin.ac.id

R. A. Buda dan M. M. Addi, “A portable non-invasive blood glucose monitoring device," IECBES 2014, Conf. Proc. - 2014 IEEE Conf. Biomed. Eng. Sci. “Miri, Where Eng. Med. Biol. Humanit. Meet," no. December, hal. 964-969, 2014.

H. Ali, F. Bensaali, dan F. Jaber, "Novel Approach to Non-Invasive Blood Glucose Monitoring Based on Transmittance and Refraction of Visible Laser Light," IEEE Access, vol. 5, no. c, hal. 9163-9174, 2017.

I. M. M. Yusoff, R. Yahya, W. R. W. Omar, dan L. C. Ku, "Non invasive cholesterol meter using Near Infrared sensor," Proc. - 2015 Innov. Commer. Med. Electron. Technol. Conf. ICMET 2015, no. November, hal. 100-104, 2016.

Q. Qomaruddin, "PENGUKURAN KADAR HEMOGLOBIN (Hb) DARAH DENGAN METODE NONINVASIF MENGGUNAKAN LASER," Instrumentasi, vol. 40, no. 1, hal. 15, 2016. 